\title{
HARDY INEQUALITY WITH THREE MEASURES ON MONOTONE FUNCTIONS
}

\section{Maria Johansson, Vladimir D. Stepanov and Elena P. Ushakova}

Abstract. Characterization of $L_{v}^{p}[0, \infty)-L_{\mu}^{q}[0, \infty)$ boundedness of the general Hardy operator $\left(H_{S} f\right)(x)=\left(\int_{[0, x]} f^{s} u d \lambda\right)^{\frac{1}{s}}$ restricted to monotone functions $f \geqslant 0$ for $0<p, q, s<\infty$ with positive Borel $\sigma$-finite measures $\lambda, \mu$ and $v$ is obtained.

Mathematics subject classification (2000): 26D10, 26D15, $26 \mathrm{D} 07$.

Key words and phrases: Integral inequalities, weights, Hardy operator, monotone functions, measures.

\section{REFERENCES}

[1] Bennett G. AND GRosse-ERdmann K.-G., Weighted Hardy inequality for decreasing sequences and functions. Math. Ann., 334 (2006), 489-531.

[2] Goldman, M. L., Sharp estimates for the norms of Hardy-type operators on cones of quasimonotone functions. Proc. Steklov Inst. Math. 2001, no. 1 (232), 109-137.

[3] Kufner A., Maligranda L. AND Persson L.-E., The Hardy inequality - About its history and some related results. Publishing House, Pilsen, 2007.

[4] KufNer A. AND Persson L.-E., Weighted inequalities of Hardy type, World Scientific, Singapore/New Jersey/London/Hong Kong, 2003.

[5] Persson L.-E., Stepanov V. D. AND Ushakova E. P., Equivalence of Hardy-type inequalities with general measures on the cones of non-negative respective non-increasing functions. Proc. Amer. Math. Soc., (8) 134 (2006), 2363-2372.

[6] ProKhorov D. V., Hardy's inequality with three measures. Proc. Steklov Inst. Math., 255 (2007), 233-242.

[7] Prokhorov D. V., Inequalities of Hardy type for a class of integral operators with measures. Anal. Math 33 (2007), 199-225.

[8] Royden H. L., Real analysis. Third edition. Macmillan Publishing Company, New York, 1988.

[9] SAWYER E., Boundedness of classical operators on classical Lorentz spaces. Studia Math., 96 (1990), $145-158$.

[10] Sinnamon G., Transferring monotonicity in weighted norm inequalities. Collect. Math., 54 (2003), 181-216.

[11] SinNAmON G., Hardy's inequality and monotonocity. In: Function Spaces and Nonlinear Analysis (Eds.: P. Drábec and J. Rákosnik), Mathematical Institute of the Academy of Sciences of the Czech Republic, Prague, 2005, 292-310.

[12] Sinnamon, G., StePanov, V. D., The weighted Hardy inequality: new proofs and the case $p=1$. J. London Math. Soc. (2) 54 (1996), no. 1, 89-101.

[13] StEPANOv V. D., The weighted Hardy's inequality for nonincreasing functions. Trans. Amer. Math. Soc., (1) 338 (1993), 173-186. 